\title{
Quantitative Analysis of CCL5 and ep300 in Periapical Inflammatory Lesions
}

\author{
Naida Hadziabdic ${ }^{1}$, Amina Kurtovic-Kozaric ${ }^{2}$, Azra Frkatovic ${ }^{3}$, Samira Smajlovic ${ }^{3}$, \\ Ariadne Letra ${ }^{4}$
}

${ }^{1}$ Department of Oral Surgery, Faculty of Dental Medicine, University of Sarajevo, Sarajevo, Bosnia and Herzegovina, ${ }^{2}$ Department of Pathology, Clinical Center of the University of Sarajevo, Sarajevo, Bosnia and Herzegovina, ${ }^{3}$ Department of Genetics and Bioengineering, International Burch University, Sarajevo, Bosnia and Herzegovina, ${ }^{4}$ Center for Craniofacial Research, Department of Diagnostic and Biomedical Sciences, School of Dentistry, University of Texas Health Science Center at Houston, Houston, TX 77054, USA

Correspondence: nsulejma@yahoo.com

Tel.: + 38761157132

Fax.: + 38733236118

Received: 4 January 2019

Accepted: 7 August 2019

Key Words: Chemokine CCL5 - E1AAssociated P300 Protein - Periapical Granuloma - Periapical Periodontitis • Radicular Cyst.

\section{Introduction}

Periapical inflammatory lesions are among the most common lesions of inflammatory origin in human jaws (1). They are characterized by destruction of the periapical tissue, resulting in surrounding bone resorption and eventual formation of cysts or granuloma (2). The development of these lesions is triggered by bacterial infection of the root canal (3). The host immune system
Objectives. In silico bioinformatical analysis suggested that the expression of two genes, CCL5 (C-C Motif Chemokine Receptor 5) and ep300 (Histone acetyltransferase p300), could be used as potential new biomarkers in differentiation between periapical granulomas and radicular cysts. Thus, we hypothesized that gene expression of CCL5 and ep300 in periapical lesions would classify the lesions as either granuloma or cyst. Materials. Patient samples $(n=122)$ included 46 periapical granulomas, 38 radicular cysts and 38 healthy gingival samples as controls. Real-time PCR analysis of CCL5 and ep300 transcripts was compared to SDHA (Succinate dehydrogenase complex, subunit A) as the reference. Clinical parameters (e.g., intensity of inflammation and lesion size) were measured and correlated with CCL5 and ep300 expression. ROC (Receiver operating characteristic) and logistic regression analyses were used to establish the diagnostic character of $\Delta$ Ct values. Results. Granulomas and radicular cysts had significantly higher expression of CCL5 and ep300 compared to controls $(\mathrm{P}<0.05)$. However, no differences were observed when comparing granulomas and radicular cysts. ROC analyses showed that CCL5 and ep300 have good diagnostic accuracy, but low accuracy for distinguishing between the lesions. Conclusions. This study confirmed that expression of CCL5 and ep300 is relevant for the pathogenesis of periapical inflammatory lesions but cannot be used as a distinctive marker between these lesions. fights the infection by recruiting different mechanisms, such as T- and B-cell-mediated anti-bacterial responses, which activate a network of regulatory cytokines that are produced by Th1- and Th2-type T-lymphocytes (1).

Many newer studies are concerned with the analysis of inflammatory mediators and biomarkers and their influence on the development of various periapical lesions (4- 
13). Pires et al. in their study analyzed the expression of a whole range of cytokines in active and inactive periapical lesions (2). Also, Cavalla et al. were engaged in understanding the expression of protein profiles in apical periodontitis for identifying potential diagnostic molecular markers in one of their recent studies (5). In everyday clinical practice, nonsurgical therapy is the first choice for treatment of periapical cysts or granulomas. Numerous studies have attempted to find new biomarkers to differentiate these entities by analysing gene or protein expression (14). Besides laboratory investigations, a bioinformatic study was recently conducted to identify genes concerned with differentiation of periapical granulomas and cysts (15). This study recommended two genes, CCL5 and ep300, as the leader genes in differentiation between periapical granulomas and cysts, respectively. However, laboratory confirmation of the role of these genes in inflammatory periapical lesions has not been conducted.

CCL5 is a cytokine that belongs to the chemokine superfamily (16). It is a natural ligand for the CCR5 receptor (C-C Motif Chemokine Receptor 5) and functions as a chemoattractant for T-cells, monocytes (17) and eosinophils (18), as well as an activator of basophils to release histamine (19). ep300 is a histone acetyltransferase that regulates transcription via chromatin remodelling and is involved in processes of cell proliferation and differentiation (20). This gene has been implicated in bone metabolism through its interactions with RANKL (Receptor activator of nuclear factor kappa-B ligand) protein (21). Also, it has been suggested that ep300 is involved in regulation of tooth initiation (22).

The present study hypothesized that CCL5 and ep300 are molecular markers for differentiation between periapical granulomas and radicular cysts. We also hypoth- esized that these potentially new biomarkers are correlated with the inflammation intensity and lesion size.

\section{Materials and Methods}

\section{Sample}

Patient samples consisted of periapical inflammatory lesions, including periapical granulomas $(n=50)$, radicular cysts $(n=59)$, and healthy gingiva samples as controls $(n=40)$. Patients with periapical granulomas or radicular cysts underwent the oral surgery procedure of periapical lesion extirpation, followed by either apicoectomy or routine extraction of the non-vital tooth/ remaining root. All the above-mentioned oral surgery procedures were conducted by N.H. After periapical lesion extirpation, the lesion was divided into two parts. One part was immersed in $10 \%$ buffered formalin and then embedded in paraffin FFPE (FormalinFixed Paraffin-Embedded) for histopathological diagnosis, and the other part was flash frozen in liquid nitrogen and stored in a freezer at $-80^{\circ} \mathrm{C}$ until the moment of RNA isolation and cDNA synthesis.

On the basis of histopathological analysis carried out by the same pathologist [S.R], all samples in the experimental group were classified either as radicular cysts $(n=59)$ or periapical granulomas $(n=50)$. Of the 59 radicular cysts, 29 samples were extirpated during apicoectomy with cystectomy, while 30 radicular cyst samples were collected during the surgical intervention for extraction of the non-vital tooth/residual root with cystectomy. Out of 50 periapical granulomas, 26 samples were collected during apicoectomy and 24 samples were collected by curettage after extraction of the offending tooth or residual root. Out of 59 samples of cysts, in 11 samples the tooth had previously been treated endodontically, while in 48 samples the tooth had not been previously endodontically treated. 
Out of 50 samples of periapical granulomas, in 13 samples the tooth had previously been treated endodontically (root canal(s) obturated with permanent filling material), while in the remaining 37 samples the tooth had not been previously treated endodontically (those were the situations where consulting endodontist insisted for endodontic surgery as first therapy option). For patients with periapical lesions a nonendodontically treated tooth, was obturated with permanent root canal filling material immediately before apicoectomy. Control group samples consisted of healthy gingiva, which was removed as excess during third molar extractions (23-25). These samples were characterized as healthy tissues on histopathological examination and as such were included in the control group $(n=40)$.

\section{Inflammation Intensity}

FFPE tissue sections were sliced at 3-5 $\mu \mathrm{m}$, stained with hematoxylin and eosin, and screened by a pathologist who was blinded to the clinical data. Intensity of inflammation was semi-quantitatively determined as follows: 1 is a mild inflammation that is found in $1 / 3$ of the field of view; 2 is an intermediate inflammation where the inflammatory infiltrate is found in $2 / 3$ of the field of view; and 3 is a severe inflammation that is found in more than $2 / 3$ of the field of view.

\section{Lesion Area Measurements}

The size of the periapical lesions was based on radio-graphical findings and measured in $\mathrm{mm}^{2}$ (largest diameter $(\mathrm{mm}) \mathrm{x}$ largest root to border distance). Lesions with a diameter larger than 10x10 mm were radiographically classified as cysts, while smaller lesions were classified as granulomas. All samples were confirmed histologically.

\section{RNA Isolation and Reverse Transcription}

RNA isolation and cDNA synthesis were conducted according to the manufacturer's protocol using a RNeasy Mini Kit (Qiagen, Germantown, MD, USA) and High Capacity cDNA Reverse Transcription Kit (Life Technologies, Carlsbad, CA, USA), respectively. The quantity of isolated RNA was measured for each sample with a spectrophotometer by measuring absorbance at $260 \mathrm{~nm}$ in $\mathrm{ng} / \mu \mathrm{l}$ (BioSpec nano-UV-VIS Spectrophotometer, Shimadzu Scientific Instruments). Besides measuring the absorbance at $260 \mathrm{~nm}$, the absorbance at $280 \mathrm{~nm}$ and $230 \mathrm{~nm}$ was measured to obtain the applicable ratios A260/280 nm and A260/230 nm, which is important for identification of purity of the isolated RNA. DNase treatment was not used.

\section{Real-time PCR}

All qPCR reactions were carried out on Stratagene Mx3005p qPCR (Agilent Technologies, Santa Clara, USA) using SYBR Green chemistry (Life Technologies, Carlsbad, USA). PCR conditions were: $95^{\circ} \mathrm{C}$ for 20 seconds and then 40 cycles of $95^{\circ} \mathrm{C}$ ( 3 seconds) and $60^{\circ} \mathrm{C}$ ( 30 seconds), followed by the standard denaturation curve. The sequences of human primers for ep300 and CCL5 were obtained from Zimmermann, Acosta, Kohlhase \& Bartsch (2007) and Lu et al. (2014), respectively $(26,27)$.

Primers for CCL5 were: Forward, CATATTCCTCGGACACCACAC, Reverse, C T T T C G G G T GA CA A A G A C GA C. Primers for ep300 were: Forward, CCAGGAGGCAGAGGTTGTAG, Reverse, AGCATCCCACAGGCCTCTAT. Fast SYBR $^{\circledast}$ Green PCR Master Mix (Applied Biosystems, Foster City, California, USA), $200 \mathrm{nmol} / \mathrm{l}$ specific primers and $1 \mu \mathrm{l}$ of cDNA were used in each reaction. Expression data were normalized to the geometric mean of the housekeeping gene SDHA (14) . 


\section{Ethics Statement}

The study protocol was approved by the Ethical Committee of the Faculty of Dental Medicine of the University of Sarajevo (No: 01-4-216-9/2017). All procedures performed in studys involving human participants were in accordance with the ethical standards of the institutional and/or national research committee and with the 1964 Helsinki Declaration and its later amendments, or comparable ethical standards. Informed consent was obtained from all individual participants included in the study.

\section{Statistical Analysis}

Delta $\mathrm{Ct}(\Delta \mathrm{Ct})$ values were calculated as the difference between the $\mathrm{Ct}$ value of the sample and $\mathrm{Ct}$ of the standard. For comparison of CCL5 and ep300 $\Delta$ Ct values, a Pair Wise Fixed Reallocation Randomization Test was performed using REST software (Relative Expression Software Tool) (28). Spearman's coefficient correlation and logistic regression analysis were used to correlate gene expression on periapical granuloma or radicular cyst development. ROC (Receive Operating Characteristic) and AUC (Area Under the Curve) were estimated to evaluate the criteria validity of $\Delta \mathrm{Ct}$ values and to find qPCR analysis diagnostic reliability (sensitivity and specificity), respectively. MedCalc software v. 17.2 (MedCalc Software, Mariakerke, Belgium) was used for these analyses. A significance level of $5 \%$ was used to determine statistical differences.

\section{Results}

Macroscopic and histopathological examples of analysed samples (radicular cyst and periapical granuloma) are shown in Figure 1. Gene expression analysis of CCL5 and ep300 genes was analysed in 50 granulomas, 59 cysts, and 40 control samples of healthy gingiva. After RNA isolation and qPCR reaction, 14 qPCR reactions were unsuccessful and were excluded from the analysis. In addition, 13 samples were excluded from the analysis because they originated from the same patients. Thus, 27 samples were excluded from the final analysis. The remaining 122 samples were statistically analysed (84 periapical inflammatory lesions and 38 controls).

The comparisons were made between granuloma vs. control, cyst vs. control, [granuloma and cyst] vs. control, and cyst vs. granuloma (Figure 2 and Figure 3). A statistically significant increase was observed in the following comparisons: ep300 expression in [granuloma and cyst] vs. control (ratio=2.475; $\mathrm{P}=0.001$ ) and CCL5 expression in [granuloma and cyst] vs. control (ratio=2.113; $\mathrm{P}=0.002$ ). Comparing granulomas vs. controls, both markers showed a statistically significant increase in expression- ep300 (expression ratio $=2.885$; $\mathrm{P}=0.000$ ) and $C C L 5$ (expression ratio $=2.397$; $\mathrm{P}=0.005$ ). Similar expression profiles were observed when comparing cysts vs. controls, and an increase in expression of CCL5 (expression ratio $=1.904 ; \mathrm{P}=0.008)$ and ep300 (expression ratio $=2.180 ; \mathrm{P}=0.003$ ) was observed. No significant differences were observed when comparing the expression of $C C L 5$ and ep300 in radicular cysts vs. periapical granulomas.

Regarding any potential correlation between CCL5 and ep300 expression with the intensity of inflammation, neither of the two markers showed any statistically significant correlation (CCL5 rho $=0.141, \mathrm{P}=0.2881$; ep300 rho $=-0.00665, \mathrm{P}=0.9601)$. We assumed that the smaller lesions would have higher CCL5 expression because this gene was originally bioinformatically identified in granulomas. Correlation of CCL5 expression and lesion surface area in $\mathrm{mm}^{2}$ was conducted and a statistically significant negative correlation was found between CCL5 


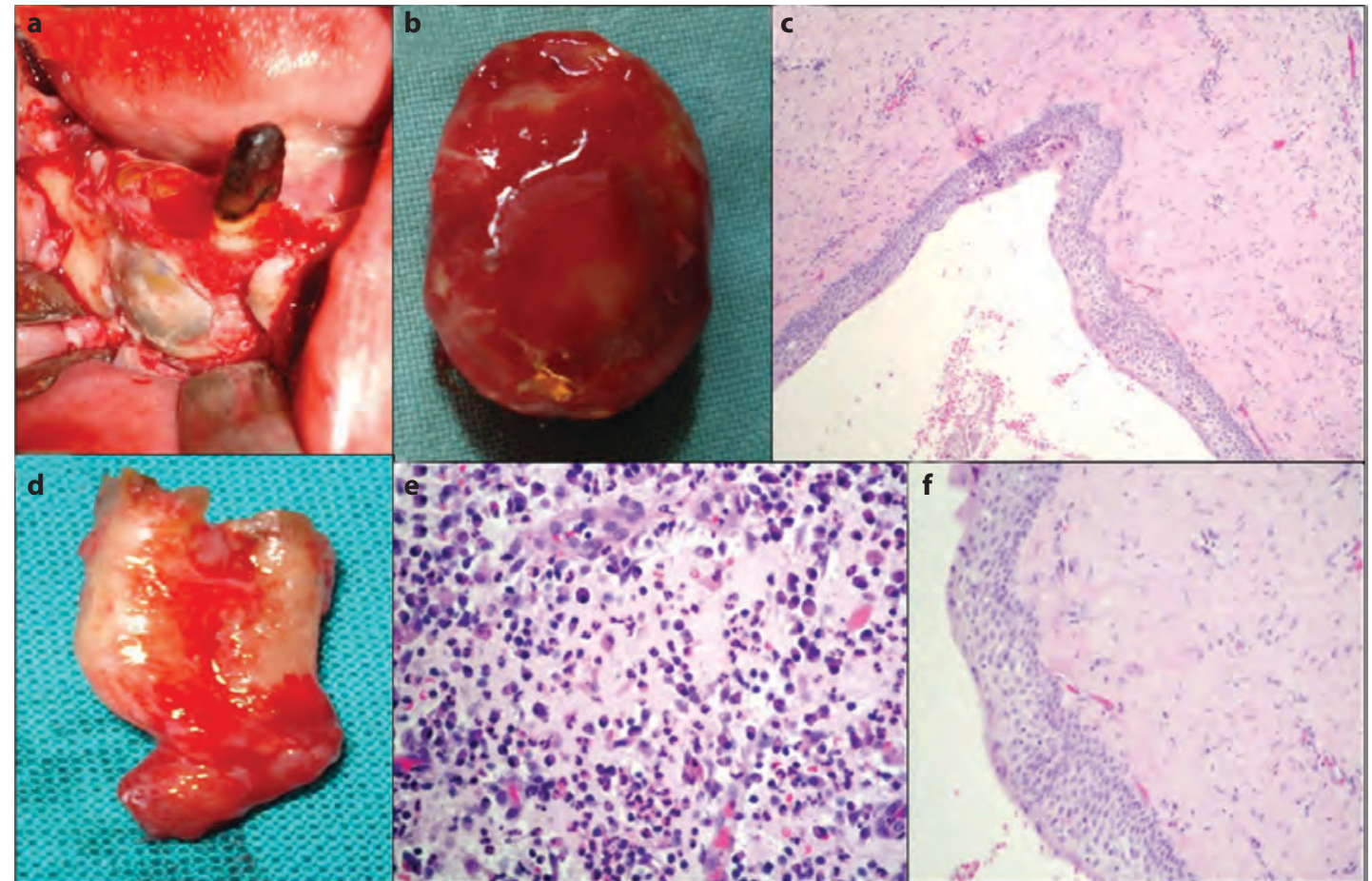

Figure 1. Intraoperative finding of a radicular cyst after raising the mucoperiosteal flap and removal of the thin bone lamella (a). Macro view of an enucleated cyst (b). Radicular cyst microscopic features: connective tissue wall infiltrated by chronic inflammatory cells, epithelial lining-stratified squamous non-keratinized epithelium $(\mathrm{HE}, \mathrm{X} 200)$ (c). Clinical appearance of granuloma on the lower left first molar (d). Chronic non-specific granulation tissue of periapical granuloma (HE, X400) (e). Healthy gingival tissue without signs of inflammation (HE, X250) (f).

A

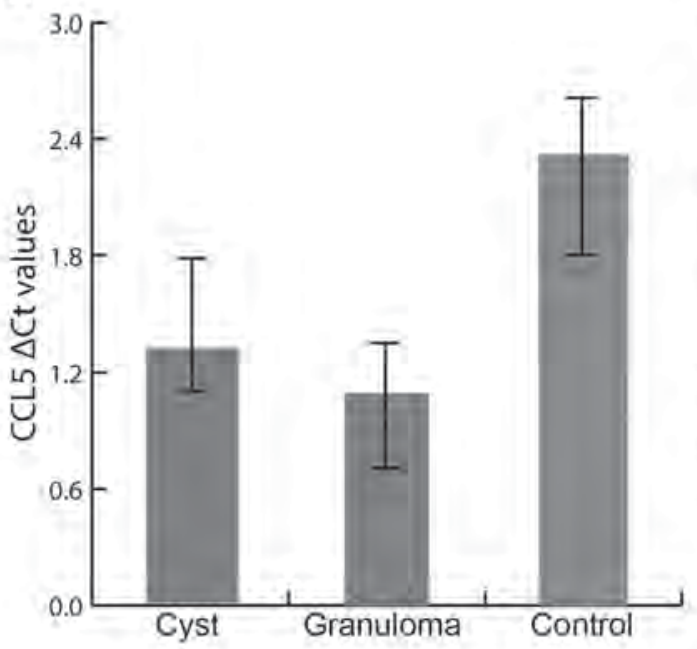

B

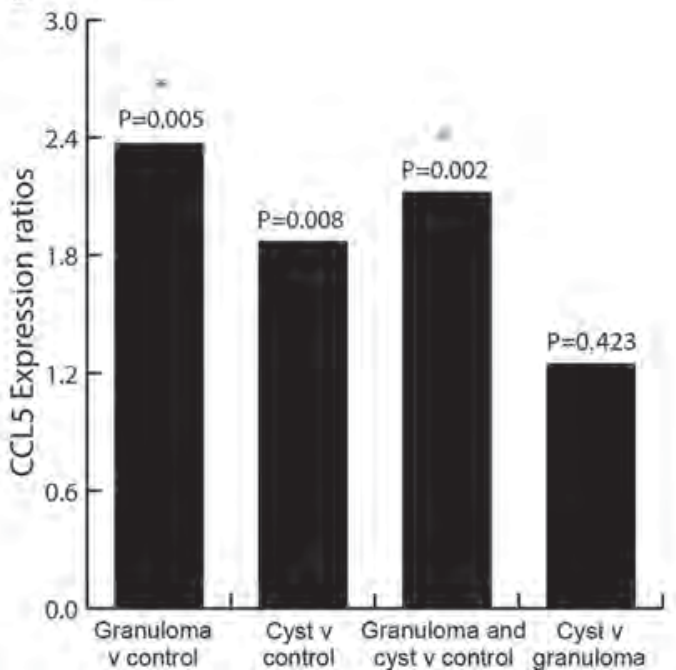

Figure 2. (A) CCL5 $\Delta C$ t values in cysts $(n=46)$, granulomas $(n=38)$ and control $(n=38)$ sample groups. $\Delta C t$ for each sample was calculated as the difference between the Ct values of CCL5 and SDHA as the standard. Values are presented as mean \pm standard error of the mean. (B) CCL5 expression ratios between granuloma vs. control, cyst vs. control, granuloma and cyst vs. control and cyst vs. granuloma. *Above indicates a statistically significant difference in expression ratios $(\mathrm{P}<0.05)$. 
A

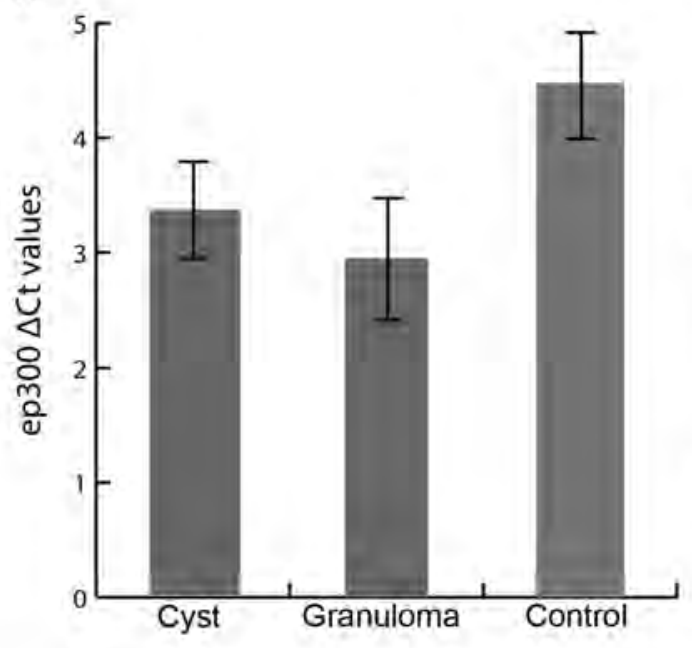

B

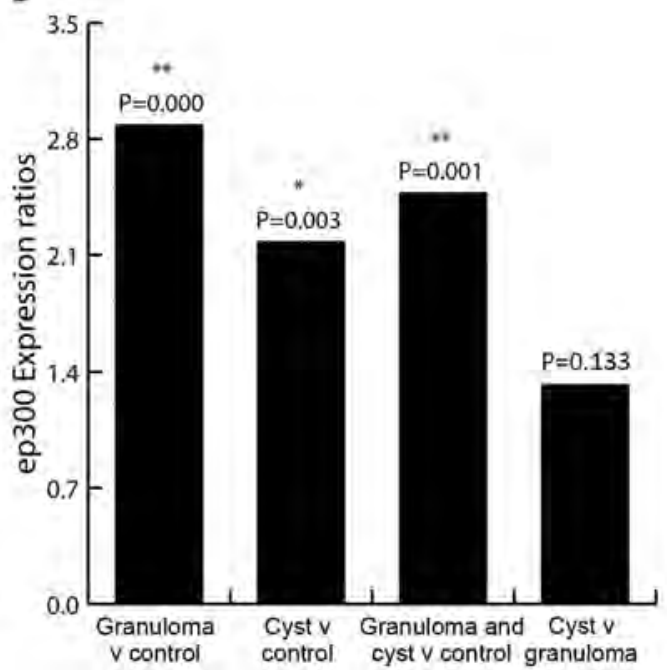

Figure 3. (A) ep300 $\Delta C$ t values in cysts $(n=46)$, granulomas $(n=38)$ and control $(n=38)$ samples. $\Delta C t$ for each sample was calculated as the difference between the $\mathrm{Ct}$ values of ep300 and SDHA as the standard. Values are presented as mean \pm standard error of the mean. (B) ep300 expression ratios between granuloma vs. control, cyst vs. control, granuloma and cyst vs. control and cyst vs. granuloma. ${ }^{*}$ Above indicates a statistically significant difference in expression ratios $(\mathrm{P}<0.05) .{ }^{* *}$ Above indicates a strong statistical significance in expression ratios $(\mathrm{P}=0.001)$.

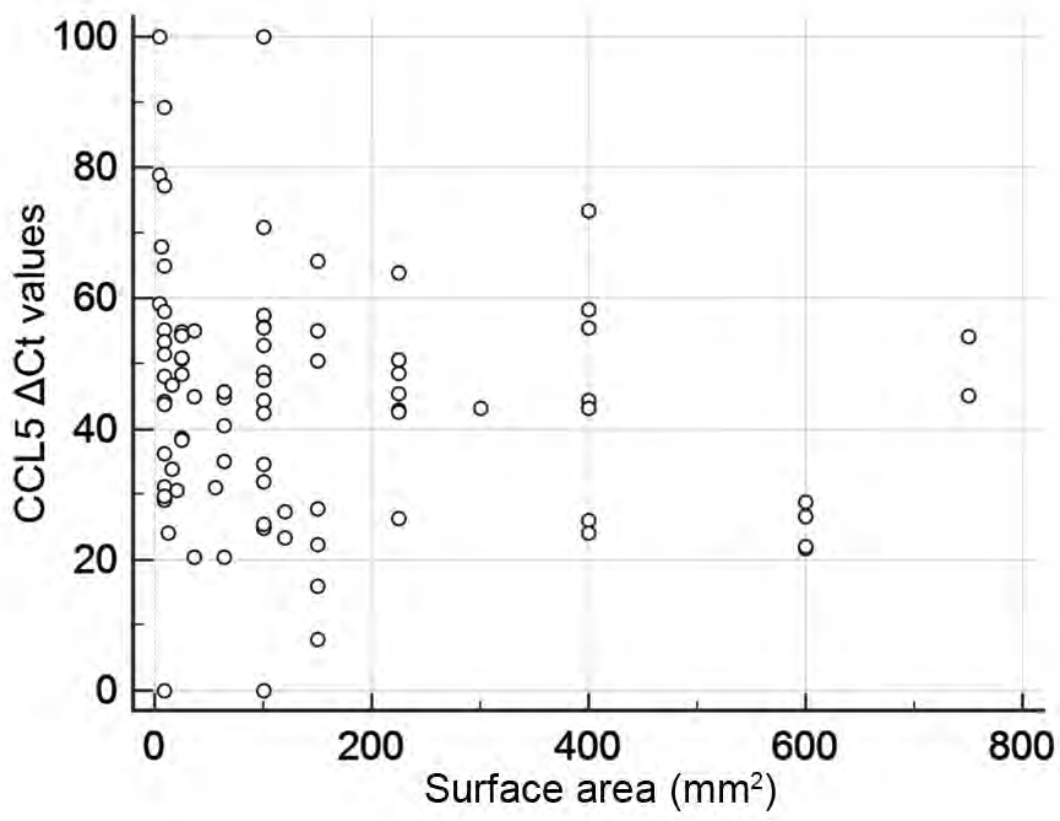

Figure 4. The correlation between $\triangle C t$ values for CCL5 and surface area. The surface area was between 4 and $800 \mathrm{~mm}^{2}$. Considering that a smaller $\Delta \mathrm{Ct}$ value implies greater gene expression, this result indicates that a greater expression of CCL5 marker is followed by a smaller surface area. 

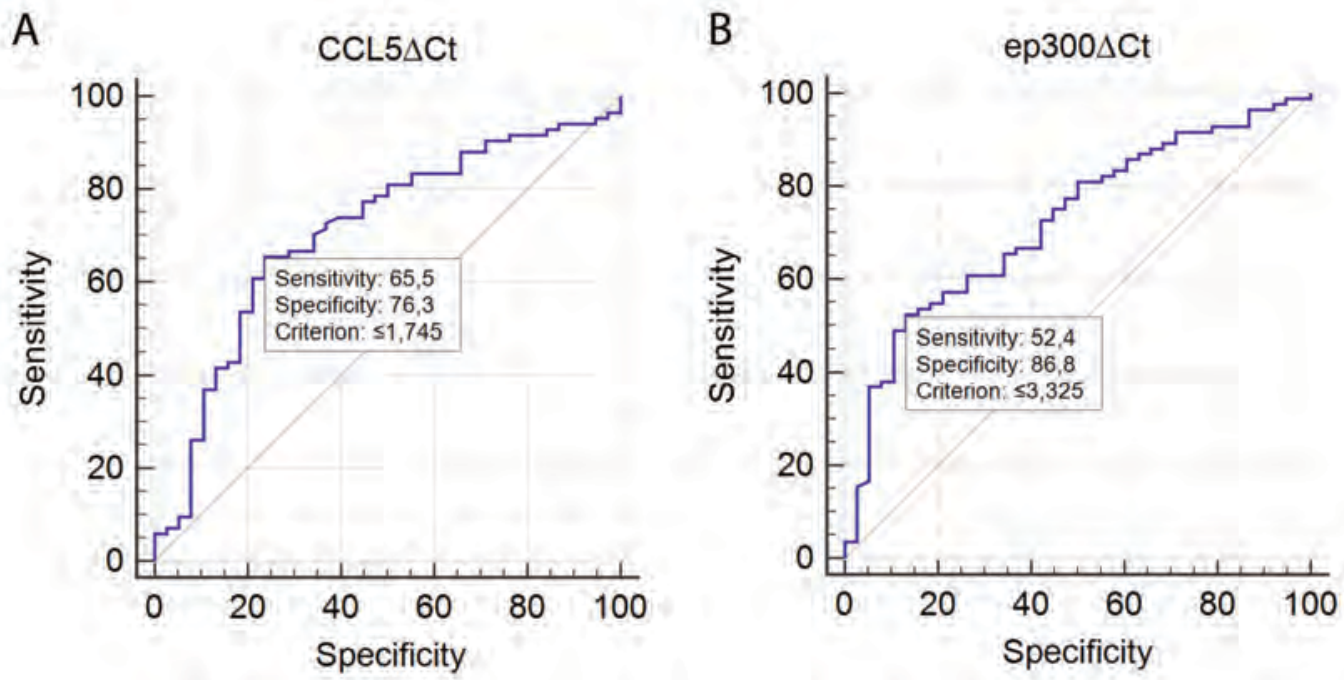

Figure 5. Sensitivity and specificity analysis of qPCR results for CCL5 and ep300 markers. A ROC curve (Receiver Operating Characteristic) was used to estimate for (A) CCL5 and (B) ep300. The AUC (Area Under the Curve) was obtained to determine the diagnostic reliability of qPCR analysis.

expression and lesion size, as hypothesized (CCL5 rho=-0.234, $\mathrm{P}=0.0320$ ) (Figure 4).

Regarding ep300, we assumed that larger lesions would have higher expression of the ep300 gene because it was bioinformatically identified in cysts. No statistically significant correlation of lesion surface area and expression of ep300 was found (ep300 rho $=0.00760, \mathrm{P}=0.9453)$.

ROC (Receiver operating characteristic) and logistic regression analyses were used to establish the diagnostic character of $\Delta \mathrm{Ct}$ values. Both CCL5 and ep300 genes were diagnostically distinct when comparing the control group and individuals with radicular cysts and periapical granulomas (Figure 5). For CCL5, ROC analysis showed good diagnostic accuracy $(\mathrm{AUC}=0.708 ; \mathrm{SE}=0.0513$; 95\% CI=0.619-0.787; $\mathrm{P}=0.0001)$. The cutoff value was 1.745 , maximum sensitivity was $65.48 \%$, and specificity was $76.32 \%$, as shown in Figure 5. The same analysis for ep300 showed good diagnostic accuracy (AUC $=0.722 ; \mathrm{SE}=0.0484 ; 95 \% \mathrm{CI}=0.634-$ 0.799; $\mathrm{P}=0.0001)$. The cut-off value was 3.325 , maximum sensitivity was $52.38 \%$ and specificity was $86.84 \%$. Neither ROC nor logistic regression analysis indicated any difference between radicular cysts and periapical granulomas (data not shown).

\section{Discussion}

One of the new trends in dentistry research is the identification of so-called "leader genes" that are important for the development of various oral diseases. Bioinformatics, which as a theoretical discipline implements information technology in the field of molecular biology, has this indisputable role. Bioinformatics brings together knowledge from various health disciplines and combines this with computer science, biostatistics, engineering and information technologies. By elaborating and analysing data from many databases, this discipline helps in scientific research work, e.g. in setting up research hypotheses etc. Bioinformatics has a special significance for dental research in the field of oral pathology. Today, there is a huge amount of information from this area that is processed by bioinformatic methods. 
This is a great help for scientists, especially in finding new ideas for experimental research. Bioinformatics itself is not enough and has many deficiencies, but in combination with experimental research it becomes a significant tool in studying the molecular pathogenesis of the disease. So, we used the research of Poswar et al. as a guide in our own research. In other words, bioinformatically identified genes (CCL5 and ep300) were experimentally tested on our own samples $(29,30)$.

For everyday clinical practice, it is essential to differentiate between periapical granulomas and radicular cysts (3). Therefore, investigation of potential specific markers for differentiation between granulomas and cysts is clinically important.

Poswar et al. (2015) conducted a bioinformatics study aimed at identifying potential gene candidates as biomarkers for differentiation between radicular cysts and periapical granulomas (15). The authors named these genes 'leader genes' that could potentially differentiate between these two lesions. For radicular cysts, the suggested leader genes were TP53 and ep300, whereas periapical granulomas were associated with $I L$ 2RG, CCL2, CCL4, CCL5, CCR1, CCR3, and CCR5 genes. In this study, we examined the expression of ep300 and CCL5 in our cohort that consisted of 38 granulomas, 46 cysts and 38 controls. In our study, the control gingival samples were excess material obtained after surgical wisdom tooth removal. Some studies use periodontal ligament as controls, but many studies use normal tissue (healthy gingiva) as the proper control $(9,10,23,24$, $31)$. There are studies that use pulp tissue of impacted wisdom teeth as the control (32). There are even studies that use non-oral tissue as control, such as placental tissues (8). Our results showed that periapical lesions have increased expression of both CCL5 and ep300 compared to the controls. However, we did not find any differences in CCL5 and ep300 expression between granulomas and cysts. We found a significantly negative correlation between CCL5 expression and lesion size; in other words, the smaller the lesion, the higher the CCL5 expression.

CCL5 codes for a chemokine, that is $8 \mathrm{kDa}$ protein, with a function in the immune system. It is expressed by T lymphocytes (CD4 and CD8) and NK cells. Another name for this gene is RANTES that stands for 'regulated on activation, normal $\mathrm{T}$ cell expressed and secreted. It plays an active role in recruiting leukocytes into inflammatory sites and it induces the proliferation and activation of NK cells. Increased CCL5 expression has been linked to a wide range of inflammatory disorders and pathologies, such as AIDS (33). Expression of CCL5 has also been implicated in osteoclast recruitment $(34,35)$. Additionally, CCL5 was reported to play a role in the differentiation of multinuclear osteoclast-like cells to active osteoclasts (36). Chemokines are likely to be involved in the expansion of odontogenic cysts.

Several studies have analysed the CCL5 protein and transcript levels in periapical inflammatory lesions. Marton et al. (2000) immunohistochemically detected CCL5 protein in 6 granulomatous periapical granulomas (37). Silva et al. (2005) analysed transcript levels in 15 granulomas, 5 cysts and 3 healthy gingiva controls, where they showed a significantly higher expression of CCL5 in cysts compared to granulomas (38). In our study, however, we did not detect any difference in CCL5 expression between granulomas and cysts.

ep300 is an epigenetic transcriptional coactivator that functions as a histone acetyltransferase $(22,39)$. Its expression is limited to blood cells including myeloid lineage cells, monocytes, T cells (CD4 and CD8), and dendritic cells. It activates HIF1A (hypoxiainducible factor 1 alpha), which is a master transcriptional regulator of cellular and de- 
velopmental response to hypoxia (40-42). The critical regulatory roles of acetyltransferases in inflammation have been reviewed by Ghizzoni, Haisma, Maarsingh \& Dekker (2011) (43). Kim et al. (2016) showed that ep300 mediated acetylation of $\mathrm{H} 3 \mathrm{~K} 18$ in osteoclastogenesis (44). Our study showed for the first time that ep300 expression was increased in periapical lesions, although no differences were found between different lesion types.

Taking into consideration the fact that radicular cysts are usually larger than granulomas, our aim was to investigate if there were any significant differences in the expression of ep300 and CCL5 between these two types of periapical lesions. According to Poswar et al. (2015), it was expected that granulomas, as the smaller lesions, would show higher expression of CCL5, while cysts would show higher expression of ep300 (15). Our study confirmed the first hypothesis regarding the CCL5 expression in smaller lesions. The expression of ep300 could not be correlated with lesion size.

\section{Conclusion}

The results of this study suggest that CCL5 and ep300 have a role in periapical lesion pathogenesis. We found that both CCL5 and ep300 were diagnostically distinctive when comparing the control group and individuals with periapical lesions, but they could not be used in distinction between granulomas and cysts.

\footnotetext{
What Is Already Known on this Topic

Most common periapical inflammatory lesions localized in human jaws are periapical granulomas and radicular cysts. These lesions are triggered by bacterial infection of the root canal and have the same origin. The golden standard to differentiate periapical granulomas from radicular cysts is histopathological evaluation. There have been some attempts to find possible biomarkers that could help clinicians to make preclinical diagnoses which could lead to better therapy options. A bioinformatic study (Poswar et al., 2016) has attempted to do this, with the aim of identifying genes that could serve as markers
}

for differentiation between granulomas and cysts. This study recommended two genes, CCL5 and ep300, as leader genes in the differentiation between periapical granulomas and cysts, respectively.

\section{What this Study Adds}

According to our knowledge no one has analyzed the expression of of CCL5 and ep300 genes in periapical inflammatory lesions. Poswar et al. conducted a bioinformatical study where they identified potential leader genes for differentiation between most common periapical lesions. For RCs, the suggested leader genes were TP53 and ep300, whereas PGs were associated with IL2RG, CCL2, CCL4, CCL5, CCR1, CCR3, and CCR5 genes. In our study, we tested the results of the above mentioned bioinformatics study where we proved that ep 300 cannot be considered diagnostically distinctive for cysts and CCL5 for granulomas. .

Authors' Contributions: Conception and design: $\mathrm{NH}, \mathrm{AKK}$ and AL; Acquisition, analysis and interpretation of data: AF, SS, NH and AKK; Drafting the article: $\mathrm{NH}, \mathrm{AKK}, \mathrm{AF}$ and SS; Revising it critically for important intellectual content: NH, AKK, AF, SS and $\mathrm{AL}$; Approved final version of the manuscript: $\mathrm{NH}$, AKK, AF, SS and AL.

Conflict of Interest: The authors declare that they have no conflict of interest.

\section{References}

1. Stashenko P, Teles R, D’Souza R. Periapical inflammatory responses and their modulation. Crit Rev Oral Biol Med. 1998;9(4):498-521.

2. Nair PN. Pathogenesis of apical periodontitis and the causes of endodontic failures. Crit Rev Oral Biol Med. 2004;15(6):348-81.

3. Nair PN. New perspectives on radicular cysts: do they heal? Int Endod J. 1998;31(3):155-60.

4. Araujo-Pires AC, Francisconi CF, Biguetti CC, Cavalla F, Aranha AM, Letra A, et al. Simultaneous analysis of $\mathrm{T}$ helper subsets (Th1, Th2, Th9, Th17, Th22, Tfh, Tr1 and Tregs) markers expression in periapical lesions reveals multiple cytokine clusters accountable for lesions activity and inactivity status. J Appl Oral Sci. 2014;22(4):336-46.

5. Cavalla F, Biguetti C, Jain S, Johnson C, Letra A, Garlet GP, et al. Proteomic Profiling and Differential Messenger RNA Expression Correlate HSP27 and Serpin Family B Member 1 to Apical Periodontitis Outcomes. J Endod. 2017;43(9):1486-93.

6. Colavite PM, Cavalla F, Garlet TP, Azevedo MCS, Melchiades JL, Campanelli AP, et al. TBX211993T/C polymorphism association with Th1 and Th17 response at periapex and with peri- 
apical lesions development risk. J Leukoc Biol. 2019;105(3):609-19.

7. Letra A, Ghaneh G, Zhao M, Ray H Jr, Francisconi CF, Garlet GP, et al. MMP-7 and TIMP-1, new targets in predicting poor wound healing in apical periodontitis. J Endod. 2013;39(9):1141-6.

8. Sadri D, Farhadi S, Shahabi Z, Sarshar S. Expression of Vascular Endothelial Growth Factor in Odontogenic Cysts: Is There Any Impression on Clinical Outcome? Open Dent J. 2016;10:752-9.

9. Makino K, Takeichi O, Hatori K, Imai K, Ochiai $\mathrm{K}$, Ogiso B. Epstein-Barr virus infection in chronically inflamed periapical granulomas. PLoS One. 2015;10(4):e0121548.

10. Wang HS, Yang FH, Li Y, Pei F, Kulkarni AB, Chen Z, et al. The expression of PD-1 and LAG-3 in periapical lesions. Am J Transl Res. 2018;10(8):267784.

11. Braz-Silva PH, Bergamini ML, Mardegan AP, De Rosa CS, Hasseus B, Jonasson P. Inflammatory profile of chronic apical periodontitis: a literature review. Acta Odontol Scand. 2019;77(3):173-80.

12. Dessaune Neto N, Porpino MTM, Antunes HDS, Rodrigues RCV, Perez AR, Pires FR, et al. Proinflammatory and anti-inflammatory cytokine expression in post-treatment apical periodontitis. J Appl Oral Sci. 2018;26:e20170455.

13. Naufel AO, Aguiar MCF, Madeira FM, Abreu LG. Treg and Th17 cells in inflammatory periapical disease: a systematic review. Braz Oral Res. 2017;31:e103

14. Hadziabdic N, Kurtovic-Kozaric A, Pojskic N, Sulejmanagic N, Todorovic L. Gene-expression analysis of matrix metalloproteinases 1 and 2 and their tissue inhibitors in chronic periapical inflammatory lesions. J Oral Pathol Med. 2016;45(3):224-30.

15. Poswar Fde O, Farias LC, Fraga CA, Bambirra W Jr, Brito-Júnior M, Sousa-Neto MD, et al. Bioinformatics, interaction network analysis, and neural networks to characterize gene expression of radicular cyst and periapical granuloma. J Endod. 2015;41(6):877-83.

16. Schall TJ, Jongstra J, Dyer BJ, Jorgensen J, Clayberger C, Davis MM, et al. A human T cell-specific molecule is a member of a new gene family. J Immunol. 1988;141(3):1018-25.

17. Taub DD, Conlon K, Lloyd AR, Oppenheim JJ, Kelvin DJ. Preferential migration of activated CD4+ and CD8+ T cells in response to MIP-1 alpha and MIP-1 beta. Science. 1993;260(5106):3558.

18. Kameyoshi Y, Dörschner A, Mallet AI, Christophers E, Schröder JM. Cytokine RANTES re- leased by thrombin-stimulated platelets is a potent attractant for human eosinophils. J Exp Med. 1992;176(2):587-92.

19. Kuna P, Reddigari SR, Schall TJ, Rucinski D, Viksman MY, Kaplan AP. RANTES, a monocyte and $\mathrm{T}$ lymphocyte chemotactic cytokine releases histamine from human basophils. J Immunol. 1992;149(2):636-42.

20. Allis CD, Berger SL, Cote J, Dent S, Jenuwien T, Kouzarides T, et al. New nomenclature for chromatin-modifying enzymes. Cell. 2007;131(4):6336.

21. Shakibaei M, Buhrmann C, Mobasheri A. Resveratrol-mediated SIRT-1 interactions with p300 modulate receptor activator of NF-kappaB ligand (RANKL) activation of NF-kappaB signaling and inhibit osteoclastogenesis in bone-derived cells. J Biol Chem. 2011;286(13):11492-505.

22. Chen Z, Gao B, Zhou X. Expression patterns of histone acetyltransferases p300 and CBP during murine tooth development. In Vitro Cell Dev Biol Anim. 2012;48(1):61-8.

23. Lin SK, Chiang CP, Hong CY, Lin CP, Lan WH, Hsieh CC, et al. Immunolocalization of interstitial collagenase (MMP-1) and tissue inhibitor of metalloproteinases-1 (TIMP-1) in radicular cysts. J Oral Pathol Med. 1997;26(10):458-63.

24. Vij R, Vij H, Rao NN. Evaluation of collagen in connective tissue walls of odontogenic cysts-a histochemical study. J Oral Pathol Med. 2011;40(3):257-62.

25. Campos K, Gomes CC, Farias LC, Silva RM, Letra A, Gomez RS. DNA Methylation of MMP9 Is Associated with High Levels of MMP-9 Messenger RNA in Periapical Inflammatory Lesions. J Endod. 2016;42(1):127-30.

26. Zimmermann N, Acosta AM, Kohlhase J, Bartsch O. Confirmation of EP300 gene mutations as a rare cause of Rubinstein-Taybi syndrome. Eur J Hum Genet. 2007;15(8):837-42.

27. Lu R, Zeng X, Han Q, Lin M, Long L, Dan H, et al. Overexpression and selectively regulatory roles of IL-23/IL-17 axis in the lesions of oral lichen planus. Mediators Inflamm. 2014;2014:701094.

28. Pfaffl MW, Horgan GW, Dempfle L. Relative expression software tool (REST) for group-wise comparison and statistical analysis of relative expression results in real-time PCR. Nucleic Acids Res. 2002;30(9):e36.

29. Giacomelli L, Covani U. Bioinformatics and data mining studies in oral genomics and proteomics: new trends and challenges. Open Dent J. 2010;4:67-71. 
30. Singaraju S, Prasad H, Singaraju M. Evolution of dental informatics as a major research tool in oral pathology. J Oral Maxillofac Pathol. 2012;16(1):83-7.

31. Hadziabdic N, Kurtovic-Kozaric A, Pojskic N, Sulejmanagic N, Todorovic L. Gene-expression analysis of matrix metalloproteinases 1 and 2 and their tissue inhibitors in chronic periapical inflammatory lesions. J Oral Pathol Med. 2016;45(3):224-30.

32. Jakovljevic A, Knezevic A, Karalic D, Soldatovic I, Popovic B, Milasin J, et al. Pro-inflammatory cytokine levels in human apical periodontitis: Correlation with clinical and histological findings. Aust Endod J. 2015;41(2):72-7.

33. Zlotnik A, Yoshie O. Chemokines: a new classification system and their role in immunity. Immunity. 2000;12(2):121-7.

34. Votta BJ, White JR, Dodds RA, James IE, Connor JR, Lee-Rykaczewski E, et al. CKbeta-8 [CCL23], a novel CC chemokine, is chemotactic for human osteoclast precursors and is expressed in bone tissues. J Cell Physiol. 2000;183(2):196-207.

35. Yu X, Huang Y, Collin-Osdoby P, Osdoby P. CCR1 chemokines promote the chemotactic recruitment, RANKL development, and motility of osteoclasts and are induced by inflammatory cytokines in osteoblasts. J Bone Miner Res. 2004;19(12):2065-77.

36. Kim MS, Magno CL, Day CJ, Morrison NA. Induction of chemokines and chemokine receptors CCR2b and CCR4 in authentic human osteoclasts differentiated with RANKL and osteoclast like cells differentiated by MCP-1 and RANTES. J Cell Biochem. 2006;97(3):512-8.

37. Marton IJ, Rot A, Schwarzinger E, Szakáll S, Radics T, Vályi-Nagy I, et al. Differential in situ distribution of interleukin-8, monocyte chemoattractant protein-1 and Rantes in human chronic periapical granuloma. Oral Microbiol Immunol. 2000;15(1):63-5.

38. Silva TA, Garlet GP, Lara VS, Martins W Jr, Silva JS, Cunha FQ. Differential expression of chemokines and chemokine receptors in inflammatory periapical diseases. Oral Microbiol Immunol. 2005;20(5):310-6.

39. Gomez RA, Pentz ES, Jin X, Cordaillat M, Sequeira Lopez ML. CBP and p300 are essential for renin cell identity and morphological integrity of the kidney. Am J Physiol Heart Circ Physiol. 2009;296(5):H1255-62.

40. Torchia J, Glass C, Rosenfeld MG. Co-activators and co-repressors in the integration of transcriptional responses. Curr Opin Cell Biol. 1998;10(3):373-83.

41. Yao TP, Oh SP, Fuchs M, Zhou ND, Ch'ng LE, Newsome D, et al. Gene dosage-dependent embryonic development and proliferation defects in mice lacking the transcriptional integrator p300. Cell. 1998;93(3):361-72.

42. Inoue $\mathrm{Y}$, Itoh $\mathrm{Y}, \mathrm{Abe} \mathrm{K}$, Okamoto $\mathrm{T}$, Daitoku $\mathrm{H}$, Fukamizu A, et al. Smad3 is acetylated by p300/ $\mathrm{CBP}$ to regulate its transactivation activity. Oncogene. 2007;26(4):500-8.

43. Ghizzoni M, Haisma HJ, Maarsingh H, Dekker FJ. Histone acetyltransferases are crucial regulators in NF- $\kappa \mathrm{B}$ mediated inflammation. Drug Discov Today. 2011;16(11-12):504-11.

44. Kim K, Punj V, Kim JM, Lee S, Ulmer TS, Lu W, et al. MMP-9 facilitates selective proteolysis of the histone $\mathrm{H} 3$ tail at genes necessary for proficient osteoclastogenesis. Genes Dev. 2016;30(2):208-19. 